\title{
Friend or Foe? Understanding Assembly Workers' Acceptance of Human-robot Collaboration
}

\author{
ANTONIA MEISSNER, Chair of Ergonomics, Technical University of Munich \\ ANGELIKA TRÜBSWETTER, YOUSE GmbH \\ ANTONIA S. CONTI-KUFNER and JONAS SCHMIDTLER, Chair of Ergonomics,
}

Technical University of Munich

\begin{abstract}
Due to rising demands on productivity and flexibility, assembly processes are currently experiencing a substantial transformation. Workstations where humans and robots work closely together are becoming increasingly popular, as they provide major advantages compared to manual assembly and full automation. Yet, human-robot collaboration (HRC) can only be successful if the workforce is willing to accept it. How assembly workers perceive HRC still has to be properly investigated. An exploratory investigation using a Grounded Theory approach was conducted to identify factors that are likely to influence workers' acceptance of introducing HRC at work. Seventeen workers with various levels of HRC experience from four different manufacturing companies were interviewed. Findings reveal that some workers perceive HRC as a threat, while others regard it as an opportunity. This perception seems to depend both on their thoughts and feelings about the technology, i.e., collaborative robots, and the organizational change associated with the introduction of this technology. Several factors related to the robot (object-related factors), the individual background of the workers (subject-related factors), and the organizational environment (context-related factors) are found to influence workers' thoughts and feelings. Implications for researchers and manufacturing companies are outlined.
\end{abstract}

CCS Concepts: • Human-centered computing $\rightarrow$ HCI theory, concepts and models; Empirical studies in HCI; User models; User studies; Field studies; Collaborative interaction; • Social and professional topics $\rightarrow$ Socio-technical systems; • Computer systems organization $\rightarrow$ Robotics; • Social and professional topics $\rightarrow$ Computer supported cooperative work; Employment issues; $\bullet$ Applied computing $\rightarrow$ Psychology;

Additional Key Words and Phrases: Technology acceptance, robot acceptance, human-robot collaboration, human-robot interaction, assembly, grounded theory, qualitative

\footnotetext{
This work is supported by the German Federal Ministry of Education and Research (BMBF) under grant number 02P15A084 (research project SafeMate), within the research program "Innovation for manufacturing, services and labor of tomorrow." Authors' addresses: A. Meissner, Chair of Ergonomics, Technical University of Munich, Boltzmannstraße 15, 85748 Garching, Germany; email: antonia.meissner@tum.de; A. Trübswetter, YOUSE GmbH, Florastraße 47, 13187 Berlin, Germany; email: angelika.truebswetter@youse.de; A. S. Conti-Kufner and J. Schmidtler, Chair of Ergonomics, Technical University of Munich, Boltzmannstraße 15, 85748 Garching, Germany; emails: \{antonia.conti, jonas.schmidtler\}@tum.de.

Permission to make digital or hard copies of all or part of this work for personal or classroom use is granted without fee provided that copies are not made or distributed for profit or commercial advantage and that copies bear this notice and the full citation on the first page. Copyrights for components of this work owned by others than the author(s) must be honored. Abstracting with credit is permitted. To copy otherwise, or republish, to post on servers or to redistribute to lists, requires prior specific permission and/or a fee. Request permissions from permissions@acm.org.

(C) 2020 Copyright held by the owner/author(s). Publication rights licensed to ACM.

2573-9522/2020/07-ART3 \$15.00
}

https://doi.org/10.1145/3399433

ACM Transactions on Human-Robot Interaction, Vol. 10, No. 1, Article 3. Publication date: July 2020 


\section{ACM Reference format:}

Antonia Meissner, Angelika Trübswetter, Antonia S. Conti-Kufner, and Jonas Schmidtler. 2020. Friend or Foe? Understanding Assembly Workers' Acceptance of Human-robot Collaboration. ACM Trans. Hum.-Robot Interact. 10, 1, Article 3 (July 2020), 30 pages.

https://doi.org/10.1145/3399433

\section{INTRODUCTION}

Modern production faces a number of challenges. Customer demands regarding the quality and variety of products are rising [56]. Manufacturing companies that want to remain competitive in global markets need to cater to these demands while keeping their costs low [65]. Assembly has a great potential for rationalization, since many processes are still carried out manually. Due to small lot sizes and a high product variability full automation is not an option. Instead, more flexible systems are needed [49]. Another challenge is the ever-aging workforce, which requires alterations of the current work environment to match their demands [86]. Lately, research has made remarkable progress in the development of collaborative systems, which provide the possibility to integrate the abilities of humans and robots [65]. These systems are becoming increasingly interesting for companies, since they are easily programmable and adaptable to different applications, while enhancing productivity and saving costs [9]. Yet, the closer humans and machines work together, the more employees' work life is going to alter. If this collaboration is to be successful, it is essential to not only think about technology. Without considering human factors, restructurings are likely to fail [35]. The imminent transformation in assembly towards collaborative workstations requires a comprehensive understanding of how people perceive this transformation and under which circumstances they are willing to accept the introduction of human-robot collaboration (HRC). Factors influencing workers' acceptance of HRC still have not been sufficiently explored [35]. This article describes an exploratory investigation undertaken to develop a framework that offers an explanation for the acceptance of HRC in assembly environments from the workers' perspective.

\section{CONCEPTUAL FRAMEWORKS}

\subsection{Acceptance}

The term acceptance is defined very heterogeneously in literature. A coherent understanding of what acceptance means and how it evolves is missing. According to Schäfer and Keppler [79], acceptance results from a process of perception, evaluation, and decision with three components having a determinable influence:

- The acceptance object, which might be a physical artefact, such as a technology, or an abstract construct, such as an idea. In this study it refers to the collaborative robot.

- The acceptance subject, which might be an individual or collective. In this study it refers to the individual assembly worker.

- The acceptance context, which summarizes all external factors. In this study it refers to all factors related to the company and workplace setting. Macro-level phenomena, such as society or culture, were beyond the scope of this study and therefore not considered.

Associated with these three components are factors that might affect acceptance [51]: objectrelated factors, subject-related factors, and context-related factors. Acceptance is, therefore, highly individual and unstable [79]. The same object within the same environment might lead to very different attitudes and behaviors across persons. Likewise, a change of external conditions might also cause a change in a person's acceptance of an object. 


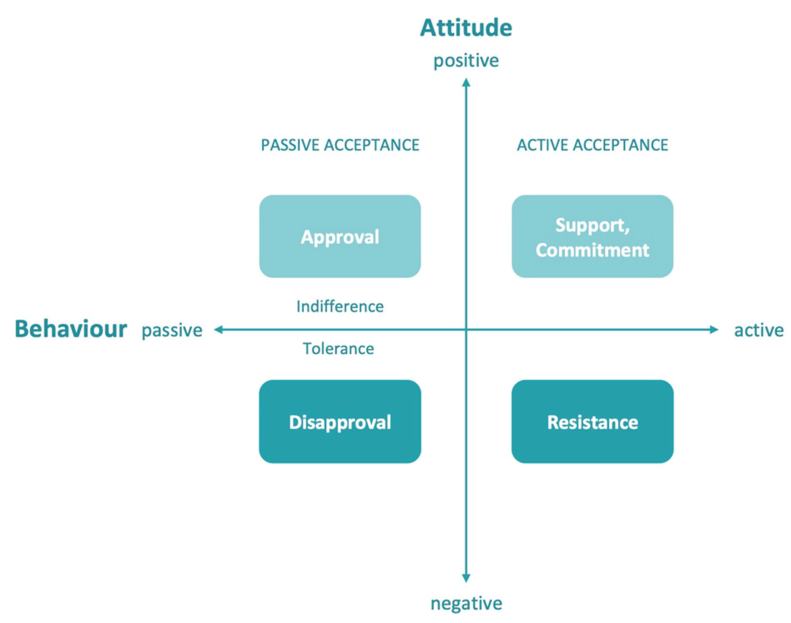

Fig. 1. Dimensions of acceptance. The upper-left quarter refers to attitudinal, the upper-right quarter to behavioral acceptance (adapted with permission from Schweizer-Ries et al. [81], p. 11).

There is also disagreement about the expression of acceptance. Commonly, research distinguishes between two dimensions [79]:

- Attitudinal acceptance, which implies a positive assessment or evaluation of an object;

- Behavioral acceptance, which can refer to buying, using, publicizing, or supporting the introduction of an object.

Many studies solely investigate the use or the intention to use a technological system as indicators of technology acceptance, which is, however, criticized. On the one hand, this approach neglects other important indicators of acceptance, such as active engagement in the implementation process of the technology [7]. On the other hand, there is a difference between voluntary contexts, where users have volitional control over their decisions to use a system, and mandatory contexts such as work, where users are forced to use a system, regardless of whether they like it or not. In mandatory contexts system use or use intentions are not adequate indicators of acceptance. Instead, the attitude towards using a system needs to be directly investigated, as it reflects users' actual satisfaction level [13]. This study follows a model presented by Schweizer-Ries et al. [81]. The authors view acceptance as a continuous construct, ranging from pure attitudinal acceptance, i.e., approval, to behavioral acceptance, i.e., support or commitment (see Figure 1). Since this study was conducted in a mandatory setting, the focus was primarily on the workers' attitudes towards HRC. In terms of behavioral acceptance, we considered not only robot use and use intentions, but also workers' engagement in the implementation process.

\subsection{Acceptance of Information and Communication Technologies}

The basis for most technology acceptance models are the theory of reasoned action (TRA) [2, 34] and its extended version, the theory of planned behavior (TPB) [1]. They postulate a causal relationship between people's intentions to behave in a certain way and their actual behavior. In turn, behavioral intentions are formed by people's attitudes towards the respective behavior and by perceived opinions of other people. 
The majority of research dealing with technology acceptance concentrates on information and communication technologies (ICT), such as the technology acceptance model (TAM) [23-25], which originated from TRA and seeks to explain the use of ICT in the organizational context. It claims that the intention to use a technology is determined by two major factors: perceived usefulness, which is "the degree to which a person believes that using a particular system would enhance his or her job performance" [24, p. 320] and perceived ease of use, which is "the degree to which a person believes that using a particular system would be free from effort" [24, p. 320]. In the final version, acceptance is operationalized only by people's behavior, i.e., technology use, but not by their attitudes [13]. TAM's simplicity is often criticized, as the model is evidently lacking in other substantial influence factors such as group, social, and cultural aspects [3]. Likewise, Legris et al. [53] claim that TAM views technology acceptance as an independent construct, although change and innovation research points to the importance of organizational dynamics. Apart from this, Bagozzi [3] notes that TAM, TRA, and TPB focus on summative constructs rather than on beliefs forming these constructs. The complex cognitive processes a user passes through are neglected.

Over the years, TAM has been revised multiple times and new models, such as C-TAM-TPB [92], TAM2 [96], TAM3 [95], and the unified theory of technology acceptance (UTAUT) [97], have emerged. Even though TAM's extensions take more determinants of technology acceptance into account, they are criticized for other reasons. Bagozzi [3] postulates that general knowledge about technology acceptance is "fragmented with little coherent integration" (p. 245) and names UTAUT as a prime example. According to him, all attempts to expand the original TAM resulted only in a broadening rather than a deepening of the model, as they do not provide a sophisticated explanation of ongoing mechanisms and interactions. All efforts made to integrate moderators remained superficial as well. Likewise, Benbasat and Barki [7] claim that "study after study has reiterated the importance of PU [perceived usefulness], with very little research effort going into investigating what actually makes a system useful" (p. 212).

Another point of criticism is that technology acceptance research is dominated by quantitative survey studies. Vogelsang et al. [98] as well as Wu [100] both point to the fact that there is hardly any methodological variance in this research field. Most studies chose prominent factors identified in previous studies and validated them with new empirical data. This caused the expression of concerns that research in the field of ICT acceptance might have reached a dead-end due to the excessive conformity with TAM and a lack of innovation [7].

\subsection{Acceptance of Human-robot Interaction}

Previous work provides several definitions of human-robot collaboration. This study follows Schmidtler et al. [80] who postulate that human-robot interaction (HRI) can be subdivided into three types:

- Human-robot coexistence, which describes two interacting entities (human and robot) operating within the same workspace at the same time;

- Human-robot cooperation, which implies two entities working within the same workspace at the same time and pursuing the same aim;

- Human-robot collaboration, which additionally requires direct physical contact between the two entities.

In this study, HRC always refers to human-robot collaboration with industrial lightweight robots that can be employed near people without being separated by safety fences. Moreover, the focus is only on dyadic interactions between one human and one robot.

Research indicates that humans perceive and assess robots differently than other technologies like ICT. Smarr [83] emphasizes that due to the uniqueness of robots, acceptance models from 
other domains might not be applicable to the field of HRI. On the one hand, robots are not an incremental, but a radical technology [32]. On the other hand, robots have several unique characteristics: Unlike other technologies, robots can act and move autonomously, interact with the physical world around them, and provide innovative forms of communication [83]. Moreover, humans tend to expect more social skills and intelligence from a robot than from other technologies. This is related to people attributing human qualities to the robot [83]. Young et al. [104] also outline that robots' physical and social presence makes people attribute agency to the robot. This results in an interaction that is essentially different from the interaction with other technologies, which eventually influences how people evaluate this interaction.

Several studies exist that claim to investigate the acceptance of HRI. There are more investigations dealing with assistive and healthcare robots than with industrial robots, which demonstrates the need for more studies in the industrial sector [78]. In the field of assistive HRI, most models are based on TAM or an extension of TAM, complemented by new factors, such as perceived enjoyment, trust, anxiety, perceived sociability (e.g., References [26, 44]), ethical factors, and worries about being stigmatized (e.g., References [41, 101]). Beer et al. [6] tried to summarize factors that influence HRI acceptance according to previous studies and found three major categories: functionality, including for example the level of autonomy; social ability, which refers to emotion expression and social intelligence; and, finally, form and appearance. In terms of acceptance, these factors can all be characterized as object-related factors, i.e., factors that refer to the design of the technology. Smarr [83] addressed the unilateral focus on robot-related factors of other studies by developing a more holistic model of assistive robot acceptance. She also included task factors and the fit between task and robot factors. Moreover, she identified several aspects influencing perceived usefulness, e.g., robot trust, and ease of use, e.g., robot anxiety. This model, however, was not empirically but theoretically derived. Generally, research reveals that the acceptance of assistive robots depends crucially on task characteristics. While robots doing housekeeping tasks are approved, most people do not want robots to execute more intimate tasks, such as shaving [84].

A large part of research in the field of industrial HRI also concentrates on the relationship between human and robot. These studies investigate primarily object-related factors, such as motion and appearance of the robot (e.g., References [11, 46, 74, 105]), interaction mechanisms (e.g., References [51, 59]), and the design of the workspace (e.g., Reference [103]). Their findings show that these factors are important, because they help people understand and predict the behavior of the robot, which is essential for trusting it and feeling safe when interacting with it. There are, however, studies that look at HRC acceptance from a broader perspective, taking subject- and context-related factors into account. Frequently, studies from the field of ICT acceptance, such as TAM, serve as starting point again. The theoretically derived automation acceptance model (AAM) by Ghazizadeh et al. [40] is based not only on ICT research, but also on findings from cognitive engineering research, which point to the fact that TAM is not able to explain technology acceptance in mandatory environments. Therefore, the model also comprises task-technology compatibility, trust, and external variables such as user and task characteristics, as well as organizational influences. It should be noted, though, that general automated systems and robotic systems tend to differ in some points, which is why these insights might not all be transferrable $[30,102]$.

An extensive model about the acceptance of human-robot cooperation in production systems, which was empirically derived, was presented by Bröhl et al. [12]. Although they dealt with a mandatory context, they did not examine attitudinal acceptance but concentrated on use intentions and use behavior. Their model combines variables from TAM, TAM2, TAM3 and additional factors, such as perceived safety, legal, and ethical considerations (e.g., fear of data security and job loss). 
Henderson [45] conducted an exploratory mixed-methods study on the acceptance of industrial robots in manufacturing. She also focused on factors not related to the design of the robot, such as robot experience, workplace culture, and the availability of training offers. Besides, she also discovered that task characteristics play an important role. There is a need for further studies due to the small sample size and the focus on only one production site.

A study that primarily concentrated on organizational enablers and barriers of a successful HRI implementation was presented by Charalambous et al. [15]. The results reveal the significance of context-related factors for HRI acceptance. For instance, communication and empowerment of the workforce were found to be enablers, whereas a poor understanding of work procedures and a bad organization of resources turned out to be barriers. Yet, additional case studies that verify the identified factors in different organizational contexts are necessary. In a follow-up study [17], the authors developed the so-called human factors readiness level (HFRL) tool, which provides a guideline on how to make use of the identified enablers and barriers in practice. Both studies make clear that for HRC to be successful in practice, it is absolutely necessary to consider human factors throughout the whole implementation process.

In conclusion, there is an extensive amount of literature in the field of HRI acceptance, broadening the insights from ICT research. Nevertheless, there still is a high potential for further research in the field of HRC acceptance in industrial environments. The present study aims to specifically address some shortcomings of previous studies:

- Many previous studies draw on existing acceptance factors from ICT research, which might be only partially transferrable to HRI acceptance. This study follows an exploratory methodology to examine if there are acceptance factors that are unique to HRI.

- The concentration on a few established acceptance models is also associated with a lack of methodological variance and possibly depth of information. Therefore, this study uses a qualitative data analysis approach.

- There is often no differentiation between voluntary and mandatory settings. Frequently, technology acceptance is operationalized as technology use. This study directly investigates attitudinal acceptance, since in mandatory environments such as organizations technology use is not always indicative of the users' attitudes.

- Many existing studies are limited to characteristics of the robot, i.e., object-related factors. This study also concentrates on context- and subject-related factors, since they are still underrepresented in literature.

\section{PURPOSE OF THE STUDY AND RESEARCH QUESTION}

The purpose of this study was to obtain a comprehensive understanding of assembly workers' acceptance of introducing HRC at work. The aim was to get away from overly investigated constructs and utilize a new, explorative approach. To address shortcomings of previous studies, we concentrated on subject- and context-related factors. Moreover, we included people with various levels of experience in working with a robot, since there is evidence that experience might affect acceptance. For instance, expectation-disconfirmation theory indicates that initial expectations of a product influence the satisfaction with the product after using it [71]. Also, longitudinal studies confirm that attitudes towards technology change with direct experience and that initial judgments influence later use intentions $[8,58]$. We specified the following research question: Which factors influence assembly workers' attitudinal acceptance of introducing HRC at work and how can it be promoted? 


\section{METHODS}

\subsection{Design}

To explore this research question, a qualitative investigation was conducted. More specifically, the aim was to collect snapshots [36] of situations before, during, and after the implementation of HRC in assembly. Data were collected by using a mixture of episodic interviews, where people are asked to freely talk about their experiences, and problem-centered interview, which uses explicit questions to collect opinions, perceptions, and associations [36].

There are many different methodologies that elaborate on how to collect and analyze qualitative data. Among the most commonly used are Grounded Theory (GT) and Qualitative Content Analysis (QCA). Whereas QCA concentrates on describing and reducing or summarizing the material, GT is more flexible and interpretative, as it seeks to inductively generate theories [Cho \& Lee, 2014]. GT is also stated to be particularly advisable for explorative research, as it "allows the researcher to look at phenomena with new eyes and from new perspective without restriction within already existing hypotheses" [18, p. 16]. We followed the GT approach by Corbin and Strauss [21], which is one of the most elaborated and structured GT approaches and well-justified in terms of scientific research [88]. The approach follows a circular and iterative process of collecting and analyzing data, while insights gained from analysis determine the source and method of data collection. Data are selected based on their likelihood of providing new insights (so called theoretical sampling), which is contrary to the linear process of many other methodologies. The process ends with the point of conceptual saturation, which is reached when according to the investigator concepts are sufficiently elaborated and new data are unlikely to provide new insights. Unique features of the analytic process include:

- Coding. This term refers to the act of gradually working through the data and extracting meaningful themes or concepts. This process goes beyond simple paraphrasing and summarizing. It rather implies deeply examining the material section-by-section and assigning codes, i.e., labels, to relevant sections, which best represent the meaning of the sections. Sections can be paragraphs, but also single sentences. While in the beginning, the investigator primarily concentrates on open coding, i.e., discovering and elaborating themes, as analysis proceeds axial coding, i.e., finding relationships between themes, is becoming more and more important. Theoretical depth arises from a well-developed network of lower- and higher-level concepts, also called categories. It is always essential to consider the context of each incident, i.e., unique conditions and circumstances. Equally important is to identify process in the data, i.e., uncovering responses of participants to situations or events, which may include feelings, actions, or interactions and which are intertwined with the respective context and unique characteristics of participants.

- Questioning and comparing. Asking questions stimulates reflections on the data and encourages the investigator to look beyond the surface and to go through different possible explanations before coming to a conclusion. Comparing findings against one another is necessary both to develop sufficiently deep concepts and to check if assumptions developed during analysis prove true. Different sections in the material might reveal different facets of the same phenomenon. Thus, comparing helps elaborate a concept in terms of its diverse properties. In case themes cannot be fully understood just by drawing on the data, it may be helpful to make theoretical comparisons with similar or contradictory ideas from other sources. Thus, the analytic process follows an alternation of inductive, abductive, and deductive analysis.

- Writing memos. This means writing down thoughts and ideas that come to the investigator's mind. As analysis proceeds, themes are evolving, relationships are emerging, and 
unexpected twists are occurring. It is impossible to grasp the whole picture right at the beginning of analysis. Hence, the analyst would not be able to generate a sophisticated theory without having a look at former ideas and elaborations. She or he should start writing memos just when starting analyzing.

Since objective criteria common in quantitative studies to assure a high research quality are not easily transferable to qualitative research, it is important to focus on "methodological consistency" [21]. For instance, continuous comparisons ensure that assumptions are tested and falsified repeatedly, which minimizes the risk of receiving a theory proving unsuitable when applied in practice [88]. Equally important is iterative data collection and analysis, enabling a comprehensive consideration of as many different perspectives and contexts as possible [88]. However, GT can only unfold its full strength when the researcher does not become too rigid in following specific rules. Ideally, there is a balance between following a systematic approach and allowing intuition [88].

\subsection{Participants}

The sample consisted of assembly workers from four German manufacturing companies from the sectors audio electronics, domestic appliances, automotive engineering, and electrical engineering. The study followed a restricted version of GT's theoretical sampling due to fixed requirements of the research project. We were not entirely free to choose participants, since the companies participating in the project had already been determined beforehand. Since no previous hypotheses had been formulated, the initial goal was to get the broadest insight possible. Throughout the process, the recruitment strategy was adapted based on insights from data analysis.

Eventually, a total of 17 participants ( 9 female, 8 male) with a mean age of $M=44.06$ years $(S D=10.44)$ were interviewed. The professional experience within the mentioned companies ranged from 3 to 32 years with a mean of $M=18.71$ years $(S D=11.05)$. Moreover, the participants differed in their team position: 4 participants occupied a team leader position, 1 participant was deputy team leader, and 1 participant, although not a team leader, was responsible for organizational and planning tasks. Their team position was related to their level of responsibility, as they all performed additional tasks besides working at the assembly line and were authorized to give instructions to other workers. Eleven participants were solely doing assembly. Concerning HRC experience, 7 participants could be regarded as truly experienced in working with a robot, as they worked daily at a human-robot workstation. Five participants had already worked with a robot in the past but were not working with one at the time of the study, and another 5 participants were completely inexperienced in working with a robot.

\subsection{Data Collection}

We used an interview guideline with open questions and a socio-demographic questionnaire that asked about age, sex, professional background, remit, and years in the company. Although Corbin and Strauss [21] advise against starting the investigation with detailed knowledge of prior findings, theoretical sensitivity towards the research field is recommended. Existing acceptance theories were therefore used to generate initial questions for the interview guideline. Besides understanding the employees' daily work and the organizational setting, we wanted to assess how much knowledge and experience they had regarding robots. Moreover, we wanted to learn more about their attitudes towards HRC and the implementation process in the company. The guideline was not used as a rigid set of questions. The interviewers rather followed the natural course of the conversation and reacted to the input of the interviewees to enable exploring new topics. To assure that participants had the same understanding of HRC, a video with two different HRC applications was shown to them after they had outlined their personal understanding of HRC. Each interview 
was accomplished by a team of two interviewers and conducted in a separate room close to the workplace of the participants. The interviews were audio recorded, provided that the participants agreed to the informed consent. The timeframe was set to 60 to 90 minutes.

\subsection{Data Analysis}

The interviews were transcribed verbatim, using the software "f5." Transcription guidelines were adopted from Kuckartz et al. [50]. Dialects were not considered and language and punctuation were adjusted to the rules of written language. Vocal expressions such as laughing or sighing were added in parentheses. Data analysis was conducted using the software "Dedoose" [85]. To assure a high analytic quality, the guidelines of Corbin and Strauss [21] were applied. Besides continuous memos, we also created summary memos after each interview to record general impressions of the participants. Moreover, questions to be answered in the upcoming analysis and ideas for the next interview phase were written down. Before the start of each interview phase, the guideline was adjusted based on the insights of the analysis. Periodically, the creation of diagrams helped get an overview of the different thematic fields and stimulate thoughts on the relationship between codes. Moreover, apart from continuous comparisons, an overall comparison of interim and end results with the raw data was done once in the middle and once at the end of the analysis. This process of deductively applying the developed coding scheme to the data resulted in modifications and further questions. We also relied on peer debriefings [36], i.e., an exchange of the main analyst with other researchers familiar with the data to check for gaps in logic and precision. Also, analytic induction, i.e., comparing hypotheses with deviant cases [36], was used to falsify hypotheses and refine the theory. The last step was to integrate the results into a coherent story. We constructed empirically grounded types [48] that result from clustering data according to certain dimensions, i.e., the most essential codes, to detect patterns in the data and to specify further hypotheses. The developed model seeks to explain HRC acceptance from the assembly workers' perspective.

\section{RESULTS}

\subsection{A Qualitative Framework for HRC Acceptance}

The analysis reveals the complexity of understanding assembly workers' acceptance of HRC. There were several insights:

- Behavior in terms of robot use is not necessarily an indication of a positive attitude towards HRC.

- The acceptance of HRC seems to depend on whether HRC is perceived as a threat or as an opportunity. This perception seems to be influenced by how workers assess the technology, i.e., collaborative robots, but also by how they assess the organizational change associated with the introduction of this technology.

- The acceptance of HRC is not only determined by rational considerations, but also largely by feelings. Both cognitive and emotional processes should be considered when investigating HRC acceptance.

First, we found that the actual use of the robot and the intention to use it are not always indicative of people's true attitudes towards HRC. Although some participants do not fully approve of HRC, most of them work with collaborative robots or express the intention to work with them. This is because job restrictions do not allow them to resist. However, many participants report to be less negative towards HRC after having personally experienced HRC, meaning that people's behavior might also affect their attitudes. Therefore, attitudinal and behavioral acceptance are 


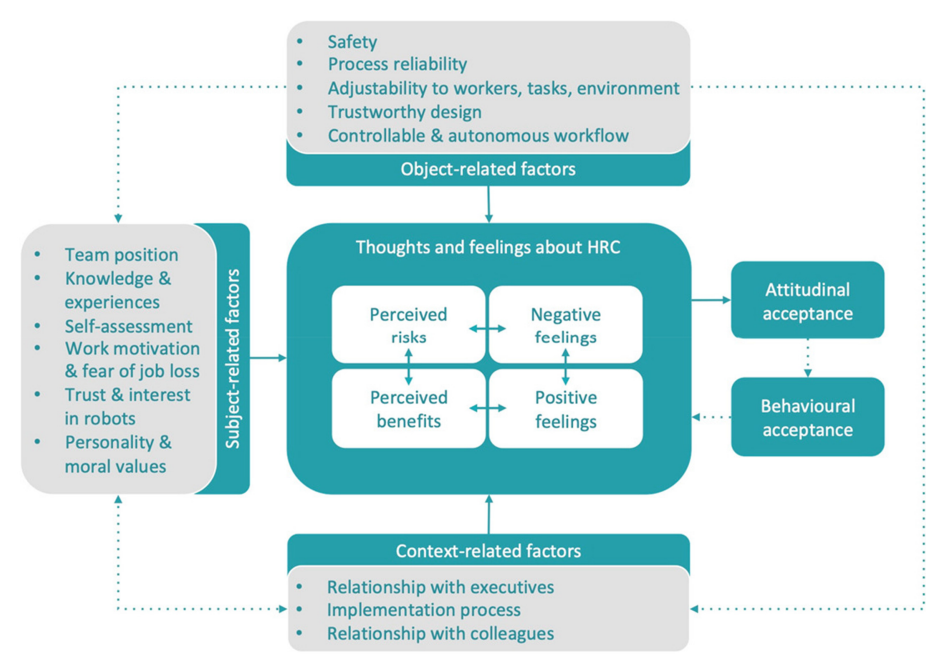

Fig. 2. Identified influencing factors on assembly workers' HRC acceptance (divided into attitudinal acceptance, i.e., approval of HRC, and behavioral acceptance, i.e., usage and support of HRC). Thoughts and feelings about HRC are identified as primary influence factors, while object-, subject-, and context-related factors are identified as secondary influence factors. Dashed arrows refer to optional interactions.

assumed to have a bidirectional relationship. Also, active engagement in the implementation of HRC seems to correspond well to people's attitudes: All the workers who participate in the implementation process have a positive attitude towards HRC. However, it does not seem true that workers who do not actively participate necessarily have a negative attitude towards HRC. Some workers simply believe that their efforts are not likely to be valued. Moreover, expressing concerns is not always easy in some companies, because they are not appreciated or ignored. These circumstances might diminish employees' will to engage.

Second, workers' acceptance of HRC turns out to depend on whether they perceive HRC as a threat or as an opportunity. Two major aspects seem to play an important role here: how workers assess the technology, i.e., collaborative robots, and how they assess the organizational change that comes along with the introduction of HRC. This means that workers might approve of the technology itself and find it useful, but still resist its implementation because of other factors related to individual or organizational dynamics.

Third, data indicate that the acceptance of HRC is not the result of an analytical process in the sense of rationalizing its pros and cons alone. To a considerable extent, acceptance appears to be influenced by people's individual feelings towards HRC and the associated changes. Thus, the evaluation of HRC as positive or negative, as a threat or an opportunity, might not always seem logical or rational from the outside. Therefore, the model we propose (see Figure 2) claims that the attitudinal acceptance of HRC is primarily influenced by two aspects:

1. People's thoughts about the risks and benefits of introducing HRC in the company;

2. People's feelings towards the introduction of HRC.

Although this separation of thoughts and feelings is artificial, as they are closely interrelated, it helps understand that acceptance is neither always rational nor can it easily be predicted or influenced. We identified several secondary factors that are likely to influence people's thoughts and feelings. For reasons of clarity, these can be grouped according to the three components of 
acceptance described above-subject, object, and context [79]-although in reality the lines are blurred:

1. Object-related factors: The perceived design of the robot/human-robot interaction;

2. Subject-related factors: The worker's individual background;

3. Context-related factors: The perceived organizational environment, including the way of implementing HRC in the company;

\subsection{Primary Influencing Factors}

\subsubsection{Perceived Risks.}

Downsizing. Many participants assume that collaborative robots are not implemented for supporting, but rather for reducing staff and consider it the first step towards full automation. This concern is strongly associated with people's position. Although team leaders mention this risk, they do not seem to feel personally affected. They mostly talk in third person while ordinary assembly workers always speak of themselves losing their jobs. Moreover, people already working with a robot consider this risk as less threatening than people still working manually.

I really think it's interesting. What is technically feasible. But what is in my mind all the time is that this arm [robot] is going to replace me one day. Then I won't be needed anymore. We [workers] literally will be discarded. (Participant D03) ${ }^{1}$

Mental underload. Some workers worry about failure-related interruptions and waiting periods as well as the low speed of the robot due to safety restrictions. Moreover, they fear increasing monotony. Monotonous work routines generally are a major problem for assembly workers and variations in the workflow are highly appreciated. Collaborating with a robot undertaking half of the operations means losing the last bit of variety. Many participants refuse getting demoted to the supervisor of robots and having to simply "push buttons" while the robot is executing their tasks. This concern is also expressed by workers already experienced in working with robots.

If the thing [robot] would permanently go on strike, that would be horrible. If I had to stand next to the robot all day and think "my goodness." That wouldn't be my thing. I must be kept busy; I must do something. For me, waiting is a catastrophe. (Participant A04)

Excessive work requirements. For many employees, working with a robot is or will be a totally new experience. People who state that they have less technological knowledge fear being overtaxed, especially if they think that they will not receive training from the company. There are concerns that in the long run, demands on the workforce will rise. Some workers believe that robots are mainly introduced for achieving a higher production rate. They are scared of having to work more and harder after the introduction of HRC.

It all changes. (...) You must always educate yourself, otherwise ... On an easy, normal level you can't keep up. You just can't keep up. (Participant A02)

Increased dependence. Several interviewees fear that HRC will restrict their flexibility. Most manual workers state to be able to flexibly organize tasks. In case of disruptions, which do not occur frequently, there are possibilities to switch to other tasks. Some participants do not want to strictly stick to a collaborative workflow without the possibility of making their own decisions regarding

\footnotetext{
${ }^{1}$ All citations are translated and do not reflect the original wording, as the interviews were conducted in German.
} 
the execution of tasks. Moreover, they worry about the robot breaking down, because they would be dependent on an engineer to repair the robot.

Decreased efficiency. Many workers think that manual work is simply more efficient than working with a robot. This is because humans working in assembly have been practicing the same actions for years and over time have become highly skilled. It would be hard to reach a comparable level with a robot. Further, they consider speed to be a major problem, since in the interest of safety, robots would not be able to act as fast as necessary.

If you've been working in assembly for a long time, you act totally different. (...) The robot deposits the part, I keep holding it in my hand all the time. (...) With the robot, all steps took longer. (...) So, for me this is like "okay, I'm waiting. I'm still waiting." (Participant D03)

Less exchange with colleagues. For many workers, contact with other people is one of the most important aspects at work. If a robot took the place of a human colleague, this would mean a deterioration of working conditions. Colleagues are also considered important for knowledge exchange and error detection, which would decrease with HRC introduction.

\subsubsection{Perceived Benefits.}

Physical and mental relief. All participants report that one of the biggest problems in assembly is physical strain due to highly repetitive tasks. Muscle- and joint pain is common. Thus, physical relief is one of the most frequently expressed advantages, both by manual workers and people already working with a robot. Many participants face a conflict between their concern of being replaced and their hope for less pain. Also, mental relief is regarded as a benefit. Many participants think that HRC will make work routines less stressful.

It's a relief compared to the past. We had to mount it ourselves, now the robot does this. It's a relief, because the remaining actions are really easy. In the past, this was more difficult. You had to make many adjustments. (Participant C01)

Decreased error rate. Most participants consider fewer errors to be a big advantage of HRC. Although people already working with robots state that those have not been perfected yet and still make mistakes, they estimate that HRC will decrease errors in the long run.

Advancement. Participants keen on working and ambitious about their professional future appreciate HRC, as it will give them the chance to develop their professional skills. These workers consider HRC as an opportunity, because they are happy to do something different and to familiarize themselves with this new technology.

You're proud of yourself, which is nice of course. (...) You refresh your technological knowledge. (...) This is really great. (Participant A04)

\subsubsection{Negative Feelings.}

Anxiety. It becomes evident that most workers highly appreciate the benefits of HRC. Yet, this appreciation cannot compensate for their anxiety about the consequences resulting from the introduction of HRC. Most notably, participants are anxious about losing their jobs, but also about deteriorating working conditions and failure. People who are already scared of unemployment due to other reasons such as relocations are particularly anxious. Several people also state that the introduction of robots is different from the introduction of other machines, because it is a greater threat. Workers with more responsibility generally show less anxiety, as they seem to consider themselves less affected. They tend to express a rather unemotional assessment of the topic compared to other workers. 
Well, of course you think about it. (...) As I heard "robot" yesterday, my first thought was "oh my god, now time has come." You think about your own workplace. (Participant D04)

Uncertainty. It turns out that a major problem is a lack of knowledge and information, which leads to feeling uncertain. Many participants are not well informed about the technological development. They cannot assess the extent and speed of robotics being introduced in assembly. When asked about their first associations when hearing "robot," a lot of people answer "empty factories" and "automotive industry," even some of those experienced in HRC. Since in assembly comparatively few robots have been implemented so far, employees obviously rely on their impressions from other industries. HRC is often regarded as the first step in a process of robots replacing humans. Moreover, participants feel insecure about the robot itself. This problem occurs before the actual implementation. One participant reports that everyone was afraid of the robot in the beginning, because they did not know how it would work and what it would look like. They had only seen autonomous industrial robots so far and had no clue of the looks and functions of collaborative lightweight robots. Finally, the biggest source of uncertainty is little knowledge about processes going on in the company. Most manual workers do not know why, when, where, and how HRC is going to be introduced. Also, during and after the installation, information transfer turns out to be a crucial factor. Some participants complain about not knowing about the next steps and future plans.

It would be nice, if something new was installed, to be informed beforehand. Not only "we're going to install a robot." What tasks will the robot execute? Or: Is he going to replace me or is he going to support me? So that people know: "Okay, I have to work with it, but it's not going to replace me.” (Participant C03)

Helplessness. Feelings of helplessness and loss of control also concern various aspects. For one thing, a lot of workers feel like being at the mercy of technological development without the possibility of resisting it. Many state that robots represent "the future" and are therefore inevitable. "You cannot fight it" is a frequently mentioned phrase. Additionally, several workers are resigned due to their limited scope of influence in the organization. When asked about their ideas regarding HRC, about what they would tell executives, several participants say that those "would not listen" anyway. Answering that question "would be pointless." Thus, being dependent on the decisions of other people who are not considered to be trustworthy appears to reinforce discontent and anxiety.

You don't have any alternatives. Unless you say "I don't want to do this. I don't like this" (bitter laugh). No, you don't have any alternatives. (Participant A02)

Worthlessness. Worthlessness refers to a feeling of not being an important and appreciated member of the organization, of not being valuable as a human worker, of being easily exchangeable and replaceable. Hence, there are different facets of worthlessness. On the one hand, it is closely linked to how much people feel appreciated in the company. Many workers are disappointed by how they are treated and state that they feel like being "a number." On the other hand, it is associated with robots doing the jobs of humans: Apart from being replaceable by other humans, being replaceable by machines seems to threaten their identity and self-confidence even more.

Everyone is replaceable. Or so it seems. If I'd say now "I'm leaving," this wouldn't be a problem. (...) You've spent years here. You helped make the company what it is today. You haven't been here just for holiday. But I don't know, it's not worth anything. (Participant D03) 
Frustration. Apart from general "change-related" feelings, there are also feelings in the interaction with a robot, which seem to affect acceptance. Some participants report to get frustrated or angry if the robot does not work properly or correspond to their expectations. This frustration seems to get stronger the longer the problems persist.

\subsubsection{Positive Feelings.}

Curiosity and excitement. There are several participants who are interested and curious about HRC and thus more willing to accept HRC at work. Some people's excitement stems from an interest in technology, while other people just look forward to better working conditions or learning new things. Some workers, who experienced HRC as enriching, are even eager for more use cases being put into practice.

It's really great in my opinion. It's a support, you know. (...) I would be happy, if it was introduced here. (Participant C04)

foy. There are not only negative feelings in the interaction with a robot. Several participants say that they enjoy working with a robot, because it is a great support or provides physical or mental relief. Joy also results from being proud to be able to handle the robot and to make personal progress.

\subsection{Secondary Influencing Factors}

\subsubsection{Object-related Factors.}

Safety. Most participants are not afraid of working with a robot so closely, as they highly trust this technology. Yet, this does not mean that safety should not be a primary focus. Rather, participants view safety as a priority factor, refusing to use the system in case of any serious risks.

Process reliability. Process reliability is also considered a priority factor, as a robot that is not capable of doing what it is designated to do is considered useless. Remarkably, participants differ in their expectations on reliability depending on their way of anthropomorphizing the robot. People who ascribe human characteristics to the robot are also more likely to accept that it can make mistakes.

Adjustability to workers. Participants expect the robot to be adjustable to the physical demands of humans (e.g., body height) and people's individual way of working (e.g., pace) to ensure physical and mental relief. Moreover, they expect high accessibility, e.g., in terms of right- and left-handed people, and usability. Participants have different opinions on what makes a robot usable: While some wish for speaking to the robot, others prefer gestures to interact with it.

Adjustability to tasks and environment. HRC should account for the need for more flexibility in production, which makes using the robot for different tasks essential. Many participants confirm this, although they are concerned about the suitability of planned or installed HRC systems for the selected tasks. They indicate that it does not make any sense to introduce collaborative robots if they do not provide any advantage to manual assembly. Another critical issue is environmental conditions. For instance, a loud environment makes voice control impossible. Likewise, operating a touch screen with wet fingers is useless.

Trustworthy design. Although most workers regard robots' visual appearance as incidental, some factors are still emphasized. All participants praise the small size and roundish form of the robots, which reduces anxiety. Some also indicate the robot should look appealing and "friendly." People differ in their ideas on how to address this aspect, though. Some appreciate a smiling face while others desire warm colors. Sudden movements are considered intimidating. Regarding the speed, 
workers face a dilemma. Everyone wants the robot to be fast enough to accomplish tasks efficiently, but high speeds are regarded as detrimental to trust and safety standards.

Controllable and autonomous workflow. Many participants fear having to conform to the rhythm of the robot and being forced into a subordinate role. They make a claim for being able to control the robot and give instructions instead of receiving instructions. Several participants also fear being highly dependent on the engineers maintaining the robots. They demand more responsibility in terms of taking care of the robot or to be able to carry out tasks manually in case of disturbances.

\subsubsection{Subject-related Factors.}

Team position. Workers' positions within their team, i.e., whether they are a team leader or carry more responsibility due to other additional tasks apart from assembly, is found to influence their attitudes towards HRC, because it is closely linked to how much they feel affected by the (imminent) introduction of HRC. Workers solely doing assembly feel more threatened by HRC, because they feel they might be easily replaceable by a machine and see their occupation in danger. In contrast, team leaders mostly interpret HRC as an opportunity to become acquainted with an innovative technology. They also show more confidence regarding their ability to adapt to changing job demands associated with the introduction of HRC.

Knowledge and experiences. Workers' knowledge about technology and robotics appears to play an ambivalent role. Participants with great technological knowledge have less irrational fears, such as robots being more intelligent than humans, but indicate more specific concerns, such as technical malfunctions. Practical knowledge, which results from experience in working with a robot, seems to reinforce people's confidence in their skills to work with a robot, which might influence their attitudes towards HRC. Knowledge in terms of information about ongoing processes in the company seems to promote the acceptance of HRC, as it reduces uncertainty and anxiety. People also report that receiving information from executives contributes to feeling valued and appreciated. Moreover, past experiences in the company contribute substantially to what people think about and expect from executives. A troubled relationship can be a great obstacle for the implementation of HRC.

Self-assessment. The results suggest that workers have distinct levels of confidence in their own abilities. Some participants are sceptical of their ability to learn how to handle and work with the robot, while others have no doubts in their skills. Apart from this, there are frequent concerns whether one would be able to learn a different task in case robots replaced workers. Participants in responsible positions are particularly more confident in their abilities and professional prospects. Moreover, self-confidence seems to depend on external support by colleagues or executives.

I think it's interesting to work with it [the robot]. I would approve of it. Because I don't have a problem with participating. I think I'm not at risk of losing my job like other colleagues with let's say 50, who don't have anything to do with this. I can teach myself those things, I can participate, I can learn this. (Participant B02)

Work motivation and fear of job loss. It turns out that the participants' work motivation differs in terms of being extrinsic or intrinsic. Some participants state that they do not care about what they do as long as they have work at all, while others claim to work for personal fulfillment. They also strive for more variety and challenges at work and are more willing to embrace changes. They consider HRC to be an opportunity for advancement. Dissatisfaction with current work procedures is not necessarily related to a desire for change. Some workers do not appreciate HRC despite their dissatisfaction, probably due to anxiety. Many people already fear job loss due to other reasons, such as relocations, and being confronted with HRC seems to increase this fear. How people assess 
the risk of being made redundant is likely to be influenced by impressions from the media or by colleagues, especially if they have little knowledge about HRC and about what is happening in the company.

Trust and interest in robots. It turns out that participants differ in their trust in the robots' reliability, i.e., that it executes tasks correctly and does not harm anybody. This seems to be associated with their perceptions of robot intelligence. At one end, there are people who feel inferior to the skills of robots and believe that employees will be replaced in the long run. At the other end, there are people who perceive robots to be machines that will never be equally intelligent as humans. A factor that might be related to higher trust is anthropomorphism. Several respondents talk about the robot like they would talk about a human colleague. Some robots are even given names. Also, workers who anthropomorphize the robot do not expect it to always work perfectly, which increases their satisfaction with HRC. Apart from trust, a general interest in robots is likely to be related to a positive attitude towards HRC, as it seems to promote openness to and curiosity about HRC. Yet, interest in robots is not necessarily related to a general technological affinity. Many participants are excited about robots, but not generally interested in technology at all.

Personality and moral values. Personality traits such as optimism, openness to new experiences, and extraversion appear to be associated with a positive attitude towards HRC. As it is not possible to determine those traits apart from explicitly asking people and assessing their way of speaking and acting, it is only an assumption to be further proved. The same is true for moral values. Participants indicate different ethical positions towards robots and HRC in general, which seems to relate to their attitudes towards introducing HRC in the company. However, this seems to be mostly true for people who feel that they are not personally affected by the introduction of HRC, like for example team leaders. They tend to worry more about general social effects of introducing robots at the workplace, whereas people who fear being replaced rather worry about their own situation.

\subsubsection{Context-related Factors.}

Relationship with executives. A primary reason why participants have negative attitudes towards the introduction of HRC is that they do not have confidence in executives' trustworthiness and reliability, i.e., they do not believe that executives will consider employees' interests. Many participants feel disappointed. They state that regardless of what executives would tell them, they would not believe them. While workers with a negative relationship with superiors are also more afraid of job cuts, workers with a good relationship tend to think that HRC is introduced to support and not to dismiss employees. This relationship is shaped by past experiences: Workers who were given a feeling of being appreciated and supported tend to have more confidence in executives' decisions. Moreover, they are more willing to compromise, because executives have complied with their needs in the past. Workers who feel like "a number" tend to have low confidence and rather assume negative motives behind executives' decisions. They also feel more helpless and are less motivated to actively engage in the implementation of $\mathrm{HRC}$, as they believe that their efforts are not going to make a difference. Apart from this, confidence in executives' expertise might be critical for workers' acceptance of HRC. Some participants have doubts about whether executives are skilled enough to successfully implement HRC.

At the moment, after everything that has happened, I wouldn't know who I would believe. Often, things have been said, which turned out differently in the end. You would need to see it. Only talking or making promises... those have been broken too often. (Participant D03) 
Implementation process. Three aspects could be identified that are particularly important when introducing HRC in the company. They are also likely to contribute to a trusting relationship with executives, which is why they should be a fundamental part of the company's corporate culture:

- Information and communication,

- Participation,

- Support.

The first one is information and communication. As outlined above, uncertainty is a great problem for workers. Little knowledge increases the risk of rumors spreading and fears arising. Being informed helps adjust to the new situation and also contributes to feeling valued and appreciated. Yet, the mere existence of information transfer is not enough. Many participants also mention the way of communicating. Taking workers' ideas and concerns seriously, treating them like equals positively affects the relationship with executives. Moreover, it is important to reflect on and overcome stereotypical assumptions. Some women report that it is hard to be taken seriously, because many people think that they are not as good in handling technology as men are. Therefore, they are often resigned and not motivated to actively engage in decisions or processes concerning technology. Also, older workers tell us that they frequently have to face prejudices of being less open to changes and new technologies, which they deny. Age-related difficulties of learning new things do not necessarily go along with little motivation.

What's really nice is that they take us seriously. It's not like they are the gods, the developers, the experts and we are the dumb workers. I mean, we workers are the last link in the chain and we're often degraded. But not here. We're all in the same boat. (Participant A04)

The second aspect is participation. All interviewees point out that being given opportunities to participate is crucial, especially when it comes to radical restructurings. Therefore, being allowed to actively engage in the implementation of HRC is important for HRC acceptance. Most workers are confident about their expertise in assembly work and sceptical that executives will be successful in establishing HRC without consulting them. However, participation should not just be a matter of form. If workers' ideas are not considered, this is likely to have the opposite effect, meaning that workers tend to think they are involved, because executives seek to legitimize their own ideas, not because they care about workers' opinions.

The last aspect is support. Several participants complain about being left alone with problems. They wish for accessible contact persons in case of disruptions. Some people working with a robot also report that the implementation process is not well planned. There is no clear division of responsibilities, which results in delays or system failures. This affects employees' daily work and their attitudes towards HRC. Furthermore, participants attach value to receiving a thorough induction. It is not unusual that workers need to teach themselves how to handle applications. Many wish for having continuous support during the first weeks. Moreover, they emphasize the importance of a "learning by doing" approach.

Relationship with colleagues. It turns out that a cooperative team helps workers who have reservations regarding HRC gain confidence in working with a robot, which affects their attitude towards HRC and their actual use of the robot. Moreover, some participants report that in times of uncertainty, a supportive team has a stabilizing function. This supportive influence seems to be particularly significant for participants with a negative self-assessment and a greater anxiety about change. Workers in more responsible positions do not seem to need this support as much. Apart from this, participants report that other team members' attitudes affect their own attitudes 
towards HRC. This seems to be particularly true for team leaders or team members who are liked and respected. It is therefore possible that the attitude of a whole team only depends on a few people.

\subsection{Summary}

Findings suggest that assembly workers' attitudes towards HRC are formed by their attitudes towards collaborative robots and their attitudes towards the organizational change related to the introduction of HRC. Therefore, within the scope of organizational HRC acceptance it does not make sense to investigate one without the other, as they are closely intertwined.

Workers' attitudes towards the technology appear to be influenced by thoughts about how HRC would affect their daily work. Participants mostly reflect on their physical and mental well-being and on the fulfillment of requirements, such as efficiency and product quality. These thoughts seem to be affected by people's trust in robots, which is related to their assumptions and expectations regarding what robots can do, how they work, and what they look like. Knowledge about and experience in working with a robot appear to play a significant role, since experienced workers differ in their assumptions from inexperienced workers. Moreover, they tend to have more confidence in their abilities to handle the robot. Generally, while the attitudes of manual workers are based on general assumptions or prior experiences, the attitudes of workers using a robot daily seem to be considerably affected by the interaction with this specific robot and their feelings regarding this interaction. Apart from trust, interest in robots is found to impact attitudes, because workers interested in technology and robotics express more curiosity to try out this technology than workers who show no interest. Overall, it can be assumed that with an increasing number of robots in the company and a gain in experience, the perceptions and attitudes of the workers are likely to change.

Workers' attitudes towards the organizational change do not seem to be necessarily related to their attitudes towards the technology. Rather, they are influenced by their thoughts about general consequences, such as job insecurity or professional advancement and their relationship with executives. It also turns out that many workers do not approach the introduction of HRC from a rational or analytic viewpoint. Feelings of uncertainty, loss of control, and anxiety are found to play a vital role. Receiving information and support from executives and being able to express concerns and ideas appear to mitigate such feelings. Moreover, those workers who generally feel that they are an appreciated part of the company tend to have more confidence in executives' decision to introduce HRC. Apart from this, a good relationship with the team and a high self-confidence seem to facilitate handling the change. Work ambitions and openness to new experiences seem to play a critical role as well.

Overall, our findings suggest that workers might perceive HRC as a threat either because they are anxious about working with a robot or about the change, which means abandoning familiar working routines without being able to assess the consequences. It turns out that many workers, though approving of collaborative robots, have a negative attitude towards the introduction of HRC due to reasons not related to the technology itself.

\section{DISCUSSION}

\subsection{General Findings}

The study supports the findings of Brown et al. [13], who highlight the importance of examining attitudinal apart from behavioral acceptance. This is because in organizational settings people's behavior, i.e., if they use the technology or not, does not necessarily reflect their true attitudes towards the technology. Although the engagement in the implementation of HRC seems to be a better indicator of people's attitudes, among those participants with positive attitudes towards 
HRC some expressed a stronger will to participate than others. This might be explained by interindividual differences in personal resources. According to TPB [1], behavior is determined by perceived behavioral control. Thus, workers who believe that their engagement has an impact are probably more motivated to engage in the implementation of HRC. Internal resources, i.e., confidence in one's abilities to deal with changing requirements, might also have an influence. Moreover, this investigation supports the hypothesis of Ghazizadeh et al. [40], who postulate that attitude and technology use have a bidirectional relationship. Classic technology acceptance models (e.g., References [24, 92]) assume a unidirectional relationship. This investigation found evidence that experience in working with a robot could influence people's attitudes towards HRC. Moreover, results suggest that active engagement might affect people's attitudes as well. The possibility to express concerns and influence decisions might mitigate negative feelings and thoughts. As employees do not have the freedom to make decisions about using HRC, being granted autonomy in other areas could be crucial. Research found that restrictions of freedom can result in reactance [67]. Some acceptance theories (e.g., References [63, 96]) also emphasize the importance of voluntariness. If people cannot decide on the use of HRC, they might start looking for control elsewhere, e.g., by being able to co-determine the tasks the robot is going to support or by having a say in the design of the workstation.

Another important insight is that the implementation of HRC means a major change for employees. Acceptance research still emphasizes the human-technology interaction. Although we can confirm that a well-designed HRC system plays an essential role, our findings suggest that it is important to take a more holistic perspective on HRC acceptance in the organizational context. It is important to keep in mind that acceptance is a complex psychological construct that cannot be "achieved" as easily as, for example, effectiveness. This investigation shows that feelings can have a profound influence on acceptance. Yet, existing acceptance studies only consider them if they are directly linked to HRC. Examples are "technology anxiety" or "perceived enjoyment" (e.g., References $[12,44,83,93,95])$. However, we observed that change-related feelings such as anxiety about future consequences or disappointment about the lack of participation were equally important. They even outweighed rational considerations about HRC and therefore are likely to have a substantial influence on HRC acceptance. Although Bröhl et al. [12] examined fear of job loss, they concentrated on its influence on robot perception, specifically on perceived ease of use, and found it to be less important. In contrast, this study indicates that fear of job loss is essential. This is because, although it might not affect people's attitudes towards the technology itself, it might affect their attitudes towards the introduction of HRC at their workplace. This indicates that subjectand context-related factors should not be neglected when investigating HRC acceptance at the workplace.

\subsection{Findings about Object-related Factors}

The importance of safety for technology and robot acceptance has already been explored by other studies $[59,103]$. In this study, safety was found to be a minimum requirement for HRC acceptance, meaning that the workers expect the robot to be safe and are likely to refuse to work with a robot if they think it might not be. We also noticed that subjective and objective safety are not necessarily the same. Therefore, although guaranteeing objective safety is absolutely essential for acceptance, it might not be enough to make people feel safe. Likewise, trying to persuade people that the interaction is safe probably is not enough either, because it is more of an emotional than a cognitive problem. Separating workspaces as suggested by You et al. [103] is not a valid solution for human-robot collaboration, as physical contact is inherent in this form of interaction. Instead, designers should pay attention to the appearance and motion of the robot. People are likely to differ in their ideas of what constitutes a trustworthy design. In this investigation, a roundish form, a 
small size, and warm colors were named. There are also insights from existing studies that provide rough guidelines concerning the motion and speed of the robot or the way of interaction (e.g., References [11, 30, 74, 99]). However, most participants in this investigation expressed strong confidence in the robot's safety. This overreliance might also be dangerous if people blindly trust the system and do not act carefully anymore $[43,76]$. It is therefore important to not only oblige workers to regular safety briefings, but also to build an understandable communication and warning mechanism.

Process reliability was also found to be a minimum requirement for $\mathrm{HRC}$ acceptance. Participants reported to get annoyed quickly when the robot was not doing what it was supposed to do. Previous studies found that unreliability might affect perceived safety and trust in the robot, particularly early in the process $[28,29,76]$. Our findings also indicate that it is not easy to rebuild trust once it has been negatively affected. Moreover, the relationship between the robot's reliability and people's trust might be influenced by their initial expectations. High expectations lead to quick disappointment in the system. This can be supported by the fact that participants who treated the robot like a human colleague and expected it to make mistakes were less annoyed by malfunctions. Yet, studies by Salem et al. [75], where faulty robots were rated more anthropomorphic and more likeable, and by Mirnig et al. [62], who detected a relationship between unreliability and likeability, but not anthropomorphism, still raise questions regarding causality. Nevertheless, one should focus not only on how to optimize the system, but also on making sure that workers have realistic expectations.

Another factor that seems to determine the usefulness of HRC is the system's adjustability to the workers' (changing) mental and physical requirements and to (changing) environmental conditions. This refers to usability, ergonomics, and the fit between the robot, the task, and the surroundings. Perceived ease of use is a basic factor of TAM [24] and models building on TAM [12, 95, 96]. Task-technology-fit was also found to be important for technology or robot acceptance [33, 40, 83]. Furthermore, some studies focused on the importance of the robot's adaptability to the users' needs in the context of service robots $[26,44]$. We noticed that companies are mostly aware of these factors. The difficulty lies in understanding environmental and user requirements and deriving adequate design specifications. A common mistake is to try to solve this challenge without involving the workforce. Even if there are experts, e.g., ergonomists, workers are much more likely to accept a system if they get personally involved. We observed that rules and guidelines are not applicable to every use case. Moreover, participants reported that they had a feeling of being heard and appreciated when being allowed to contribute to setting up their own workstation. The positive effect of self-determination on the acceptance of changes is well known [38]. Thus, the importance of context-related factors, such as participation, should not be underestimated. An HRC system might fulfill all theoretical guidelines, but still not be accepted by the users. Therefore, executives should focus less on ticking off predefined criteria than on involving the workforce and finding out what really matters to them.

Also, there was a great desire for autonomy and control. Many workers reported that they did not want to be completely dependent on the robot. They preferred to at least have the option of making decisions and taking control. Although safety concerns were named as one cause, other motives seemed more important. Many people stated that handing over control felt like admitting that robots were superior to human workers. Considering that many workers feared being replaced by robots, it seems reasonable that they want to be in charge of the process. This is in line with previous studies that showed that autonomous systems are more threatening to people than systems controlled by humans $[87,106]$. However, we also observed that a feeling of loss of control could be compensated by giving people responsibility in other areas. One possibility could be to empower people to carry out small adjustments themselves, which would make them feel 
more qualified and appreciated as human workers. Again, we conclude that apart from the actual design of the human-robot interaction, it is about the "soft" factors that determine a system's acceptance.

\subsection{Findings about Subject-related Factors}

Team position was found to determine people's acceptance of HRC, because it was closely linked to their perceptions about the personal threat posed by the introduction of HRC. Although team position as such has not been investigated so far, it is indirectly reflected in other factors, such as knowledge and experiences, self-assessment, and work motivation. This is because people's positions determine which tasks they are responsible for and how they assess their professional future. Knowledge about technology and robots in particular, as well as experience in working with the respective technology, are factors that are highlighted frequently in other studies $[5,12,68,96$, 97]. Beyond that, we found that company-related experiences could also influence HRC acceptance. Participants who had made positive experiences in the past trusted executives' decisions, even if they were sceptical about HRC. Those, however, who had made negative experiences refused most changes ordered "from above." However, executives tended to think that their employees' negative attitudes towards HRC resulted from their refusal of robots, which was, however, seldom the case. Therefore, it is vital to analyze the reasons for resistance and develop a suitable strategy.

Self-assessment is mostly addressed by the concept of self-efficacy in HRI research [12, 20, 95], which refers to the "individual's control beliefs regarding his or her personal ability to use a system" [95, p. 278]. The understanding of self-efficacy in this study adds a dimension that goes beyond the pure assessment of handling the robot: confidence in being able to adapt to the new situation or find a new occupation. This aspect accounts for the fact that workers do not only have to deal with a new technology at work but with a whole change process. This is in line with Lazarus' [52] appraisal theory, which assumes that stress is caused if a stressor is considered threatening and personal resources, i.e., the perceived ability to deal with the situation, are not sufficient. At work, self-efficacy was also found to affect several organizational parameters, such as work motivation, engagement to learn new tasks, and satisfaction (e.g., References [4, 47, 57]).

Work motivation as such has, to our knowledge, not been examined yet in the context of HRC acceptance, but the intrinsic motivation to use a system was found to positively affect technology and service robot acceptance (e.g., References [26, 94]). Intrinsic motivation as opposed to extrinsic motivation relates to doing something without expecting an external reward [26]. Work motivation as defined in our study suggests a similar mechanism: Workers whose work motivation is not only to earn money look for challenges at work and are interested in $\mathrm{HRC}$, because they appreciate new experiences. There is also evidence that job insecurity is negatively correlated with intrinsic motivation [82]. It is well known that robots trigger severe fears of unemployment in different occupational fields $[27,60]$, which became apparent in this study, too. However, we also observed that giving employees a feeling of being a valuable part of the company could mitigate fears, suggesting a close link between subject- and context-related factors. The influence of corporate culture on different acceptance factors should therefore be examined further.

Trust in the system's proper functioning and its relation to acceptance have already been extensively investigated in the field of ICT [19], assistive robots [39, 44, 83], industrial robots [16], as well as automation [40]. Moreover, a number of studies suggest that robot trust has similar antecedents as robot acceptance such as characteristics of the robot, individual factors such as experience or personality, and environmental factors such as task type or use setting, while robot characteristics seem to have the strongest impact on trust $[43,70]$. Although we could not quantify the influence of different variables in our study, robot-related factors seemed to play a critical role. Nevertheless, our findings also suggest that previous beliefs about robots and the way people 
are informed about the introduction of HRC affect trust to a considerable extent, too. Therefore, we think that executives should not underestimate their power and responsibility to carefully familiarize employees with the topic. Mcknight et al. [61] stress the importance of differentiating between initial and knowledge-based trust, which draws on direct experiences with a technology. This investigation encourages this postulation, as participants experienced in working with a robot expressed different beliefs of what a robot could or should do than inexperienced participants. Charalambous et al. [14] also indicate that trust is formed by the operator's mental model of the robot. To foster initial trust, they propose that operators should not only be trained in how to use the robot, but also provided with knowledge about the robot's abilities. We also recommend making use of people's tendency to anthropomorphize technology. We observed that giving names to robots was a strategy chosen by some workers to make them feel more comfortable. There is also evidence that anthropomorphism is related to the willingness to work with the robot [69]. To promote continuous trust, Charalambous et al. [12] propose that operators should be empowered to rectify errors, as this would extend their understanding of the robot. We observed that many workers would be open to and grateful for such opportunities. The other component of trusttrust in not being harmed-could also be compared to "robot anxiety" (e.g., References [12, 44]). In this investigation, most workers were not anxious about robots, which was why it was hard to assess its influence on their attitudes. There was evidence, though, that experience in working with robots could mitigate anxiety. Thus, giving workers the opportunity to get in contact with the robot early on might be a good way to reduce anxiety and establish trust.

To our knowledge, the relationship between interest in robots and HRC acceptance has not been investigated so far. Reich and Eyssel [73] found a positive impact of a general interest in science and technology on the attitude towards service robots. Moreover, Lin et al. [54] examined "technological readiness," which refers to the willingness to use new technologies. It should be further examined if interest in robots is really a distinct concept or if it is closely linked to the openness to trying out technologies or a general, personality-related openness to new experiences.

The influence of personality traits and moral values was difficult to assess based on a qualitative investigation. Participants who expressed a general openness towards new technology and who were more optimistic about the future also tended to be more positive about robots. We know from ICT research that personality traits correlate with technology acceptance (e.g., References [31, 89]). In the field of robotics, studies found a positive relationship between extraversion and attitudes towards robots $[22,66,73]$, although they concentrated on service robots. Extraversion was also found to correlate with anthropomorphism behavior [76], which, in this investigation, appeared to positively affect people's attitudes towards robots. Regarding openness to new experiences, findings are contradictory $[22,64,66]$. Further investigations are necessary, particularly in industrial environments. Since personality traits are regarded as relatively stable and hard to influence from the outside, it is difficult to derive strategies for organizations. Yet, this investigation shows that an optimistic and positive way of approaching new situations also depends on corporate culture, meaning that organizations should not dismiss refusal against HRC as a purely individual problem. The influence of moral values on HRC acceptance has not been investigated yet. It would be interesting to see how ethical concerns arise. In this investigation, many participants had false ideas about robots, which might lead to the conclusion that in most cases ethical concerns are not based on solid research, but rather originate from little knowledge about robots, which partly lies in the organization's responsibility.

\subsection{Findings about Context-related Factors}

An important insight of this study is that technology acceptance is likely to be linked to the acceptance of changing working conditions. Research shows that people tend to prefer the status 
quo, even if a change would provide benefits, which is also known as "status quo bias" [77]. Much can be learned from organizational change research about how to address this dilemma. A literature review reveals the importance of understanding, integrating, and supporting the people affected by a change (e.g., References [10, 55, 67, 91]). Lorenzi and Riley [55] point out that it is a frequent problem that those who design and implement a new system do not perceive it as a major change, while operators do. Thus, what often happens is a one-sided focus on technological aspects while neglecting human factors. Charalambous et al. [15] investigated human factors that need to be considered when introducing HRC in companies. Although they had a more general focus on a successful (rather than an accepted) introduction of HRC, many factors concerning the implementation process were also found in this investigation, such as communication, participation, and support of the workforce. We can add the insight that these recommendations are not easily applicable if the relationship between workers and executives is disrupted, because workers might not trust executives' statements. Corporate culture, which has a strong impact on the employer-employee relationship, has been neglected in technology acceptance research. However, organizational change research emphasizes that trust in supervisors and the organization has a substantial influence on the employees' attitude towards change. Without a trusting corporate culture, the workforce is likely to disapprove of restructuring measures [72]. This implies that an employee-centered implementation process of HRC is crucial, but not enough. Rather, building a trusting relationship is a long-term task that should actively be enforced by executives.

The supportive influence of colleagues was considered by some other studies, subsumed under the term "facilitating conditions" (e.g., References [93, 97]). However, most studies did not investigate this category in further detail, which decreases its practical value. Sykes et al. [90] conducted a more detailed investigation of peer support. They state that a strong social network helps employees cope with a system, as it gives them access to information and support. Considering that robots are a radical technology that most people have not personally experienced yet, a supportive environment might be even more important. Apart from this, "social influence" in terms of other people's opinions about robots was found to affect attitudes towards robots (e.g., Reference [44]), which we can support. In organizational contexts, this can be particularly problematic, as it is hard to control team dynamics. When assessing attitudes towards robots, there should be a special focus on team leaders, who have a closer relationship with workers than executives.

\section{PRACTICAL IMPLICATIONS}

This investigation provides several insights that can be useful for practitioners looking for ways to foster their employees' acceptance of HRC. The right design of HRC workstations turns out to be a minimum requirement for $\mathrm{HRC}$ acceptance. It is necessary for workstations to really serve the demands of the tasks and the needs of the workers. This can be assured if current ways of working are analyzed timely and if workers are included into the planning and implementation process. On the one hand, there should be a special focus on mental and physical demands. One of the biggest concerns of the participants in this study was to be over- or underchallenged. Also, physical relief was vital for them, since many suffered from major physical burdens. On the other hand, workers worried about an increased dependence on the robots and on the engineers maintaining the robots. This need for autonomy might be addressed by giving them more responsibility. However, it becomes clear that good design is not the only relevant factor when it comes to HRC acceptance.

Besides, companies should actively enforce acceptance by developing a solid implementation strategy as early as possible to account for the fact that the implementation of HRC means a substantial change to most employees. Although on-the-job experience was found to positively affect acceptance, it turned out that many factors that hinder people's acceptance would not sort themselves out just by letting time pass. A first important step is to assess the status quo in terms of 
corporate culture, which also includes the relationship between employees and executives. Findings suggest that negative starting conditions can be a great barrier for the acceptance of HRC. Executives should assess what employees think about HRC and try to understand the reasons for scepticism. This also prevents executives from being guided by stereotypical conceptions about certain groups of people, e.g., of older workers being less open to HRC. Communication and participation strategies should be based on the insights collected in the beginning. Workers who fear being replaced should be addressed differently than workers who simply have doubts regarding the usefulness of the system. Since feelings of uncertainty and helplessness are a problem, enumerating benefits of HRC might not be enough. People require detailed explanations about what is happening and when or why it is happening. Following Frey and Jonas' [37] theory of cognitive control, giving staff the opportunity to understand, predict, and influence the situation might reduce negative feelings. However, it can be helpful to reinforce positive feelings by arousing people's interest in the topic, e.g., by providing opportunities to get in contact with a collaborative robot beforehand. This can also serve their trust in the new machine. Throughout the whole process, the most important aspect to keep in mind is to acknowledge people's knowledge and experience, since lacking appreciation is one of the greatest barriers to acceptance. Yet, there is no golden path to promoting acceptance. Continuously evaluating strategies and measures is thus essential to a successful implementation of HRC.

\section{LIMITATIONS}

Several limitations of this investigation should be noted. Participation in the interviews was voluntary, which might have led to a bias in the selection of participants. A general problem of this type of investigation is that attitudes are often implicit and difficult to access [42]. To gather implicit attitudes, additional methods that do not rely on narratives, such as observations, should be considered in the future. Furthermore, the study sought to gather information about the participants' behavior. Yet, due to the method, only self-reported behavior could be ascertained. Also, when collecting and analyzing interview data, it is impossible to guarantee that all relevant aspects are considered. Moreover, researchers always frame and interpret data in a certain way. The sampling was not perfect either. Besides the restricted theoretical sampling approach, there are several factors that were neglected, such as the companies' industry sector, which is related to the type of assembly task, or the cultural background of participants. A general limitation of qualitative methods is that they do not allow for definite statements regarding the relationships between factors. All findings require verification by quantitative studies. Moreover, the generalization of findings to apply to other occupational areas apart from assembly and other sectors apart from the included is not possible. Larger samples including more companies are needed.

\section{CONCLUSIONS}

The results of this study suggest that assembly workers' acceptance of HRC is likely to be influenced by a complex interplay of different factors, many of which have already been identified in previous studies. It turned out that the use of collaborative robots at work is not necessarily an indication for a positive attitude towards HRC. Engagement in the implementation process seems to be a better indicator. We also found that workers' attitudes towards HRC depend significantly on whether they perceive HRC as a threat or as an opportunity. This seems to be influenced not only by rational considerations about the risks and benefits of HRC, but also by individual and sometimes irrational feelings. Our findings suggest that the acceptance of the change process associated with the introduction of HRC is at least as important as the acceptance of the technology itself. Therefore, we conclude that a safe and well-designed robotic system is a necessary but not a sufficient condition for the acceptance of HRC. Researchers and companies alike should 
consider HRC acceptance not only a technological but also a cultural issue. They might benefit from integrating insights from different research areas, including social and economic psychology-in particular, organizational change. Moreover, robots should be treated differently than other technologies, such as ICT, since employees are likely to perceive robots as a more drastic change.

As a next step, a quantitative follow-up study is conducted to verify the detected factors and find out more about their interrelations, as well as the relationship between attitudes and behavior. However, there is still a need for more qualitative or mixed-methods investigations, as such investigations offer the opportunity to explore concepts in greater depth. We also encourage researchers to find out more about the complex interplay and interdependence of the identified factors. Finally, there ought to be further studies on long-term acceptance of industrial HRC to investigate whether certain variables become more or less important over time.

\section{REFERENCES}

[1] Icek Ajzen. 1991. The theory of planned behavior. Organiz. Behav. Hum. Dec. Proc. 50, 2 (1991), 179-211. DOI: https://doi.org/10.1016/0749-5978(91)90020-T

[2] Icek Ajzen and Martin Fishbein. 1980. Understanding Attitudes and Predicting Social Behaviour. Prentice Hall, Englewood-Cliffs, NJ.

[3] Richard P. Bagozzi. 2007. The legacy of the technology acceptance model and a proposal for a paradigm shift. f. Assoc. Inf. Syst. 8, 4 (2007), 244-254.

[4] Albert Bandura. 2009. Cultivate self-efficacy for personal and organizational effectiveness. In Handbook of Principles of Organizational Behavior. Indispensible Knowledge for Evidence-based Management, Edwin A. Locke (Ed.). John Wiley \& Sons, Inc, Chichester, UK, 179-200.

[5] Christoph Bartneck, Tomohiro Suzuki, Takayuki Kanda, and Tatsuya Nomura. 2006. The influence of people's culture and prior experiences with Aibo on their attitude towards robots. AI Soc. 21, 1-2 (2006), 217-230. DOI : https://doi. org/10.1007/s00146-006-0052-7

[6] Jenay M. Beer, Akanksha Prakash, Tracy L. Mitzner, and Wendy A. Rogers. 2011. Understanding Robot Acceptance. Technical Report HFA-TR-1103. Georgia Institute of Technology, Atlanta, GA.

[7] I. Benbasat and H. Barki. 2007. Quo vadis TAM? J. Assoc. Inf. Syst. 8, 4 (2007), 211-218.

[8] Anol Bhattacherjee and G. Premkumar. 2004. Understanding changes in belief and attitude toward information technology usage: A theoretical model and longitudinal test. MIS Quart. 28, 2 (2004), 229-254.

[9] Richard Bloss. 2016. Collaborative robots are rapidly providing major improvements in productivity, safety, programing ease, portability and cost while addressing many new applications. Industr. Robot 43, 5 (2016), 463-468. DOI : https://doi.org/10.1108/IR-05-2016-0148

[10] Prashant Bordia, Elizabeth Hobman, Elizabeth Jones, Cindy Gallois, and Victor J. Callan. 2003. Uncertainty during organizational change. Types, consequences, and management strategies. f. Bus. Psychol. 18, 4 (2003), 507-532. DOI : https://doi.org/10.1023/B:JOBU.0000028449.99127.f7

[11] D. Bortot, M. Born, and K. Bengler. 2013. Directly or on detours? How should industrial robots approximate humans? In Proceedings of the 8th ACM/IEEE International Conference on Human-Robot Interaction (HRI'13), Hideaki Kuzuoka, (Ed.). IEEE, Piscataway, NJ, 89-90.

[12] Christina Bröhl, Jochen Nelles, Christopher Brandl, Alexander Mertens, and Christopher M. Schlick. 2016. TAM reloaded: A technology acceptance model for human-robot cooperation in production systems. In Proceedings of the 18th International Conference on Human-Computer Interaction, Proceedings, Part I, Constantine Stephanidis, (Ed.). Communications in Computer and Information Science. Springer, Cham, 97-103. DOI : https://doi.org/10.1007/9783-319-40548-3_16

[13] S. A. Brown, A. P. Massey, M. M. Montoya-Weiss, and J. R. Burkman. 2002. Do I really have to? User acceptance of mandated technology. Euro. F. Inf. Syst. 11, 4 (2002), 283-295. DOI : https://doi.org/10.1057/palgrave.ejis.3000438

[14] George Charalambous, S. R. Fletcher, and P. Webb. 2016. Development of a human factors roadmap for the successful implementation of industrial human-robot collaboration. In Proceedings of the International Conference on Human Aspects of Advanced Manufacturing, Christopher Schlick and Stefan Trzcieliński, (Eds.). Springer, Cham, 195-206.

[15] George Charalambous, Sarah Fletcher, and Philip Webb. 2015. Identifying the key organizational human factors for introducing human-robot collaboration in industry. An exploratory study. Int. f. Adv. Manufact. Technol. 81, 9-12 (2015), 2143-2155. DOI : https://doi.org/10.1007/s00170-015-7335-4 
[16] George Charalambous, Sarah Fletcher, and Philip Webb. 2016. The development of a scale to evaluate trust in industrial human-robot collaboration. Int. J. Soc. Robot. 8, 2 (2016), 193-209. DOI : https://doi.org/10.1007/s12369-0150333-8

[17] George Charalambous, Sarah R. Fletcher, and Philip Webb. 2017. The development of a human factors readiness level tool for implementing industrial human-robot collaboration. Int. f. Adv. Manuf. Technol. 91, 5-8 (2017), 2465-2475. DOI : https://doi.org/10.1007/s00170-016-9876-6

[18] Ji Y. Cho and Eun-Hee Lee. 2014. Reducing confusion about grounded theory and qualitative content analysis: Similarities and differences. Qualit. Rep. 19, 32 (2014), 1-20.

[19] Erin Cody-Allen and Rajiv Kishore. 2006. An extension of the UTAUT model with e-quality, trust, and satisfaction constructs. In Proceedings of the ACM SIGMIS CPR Conference on Computer Personnel Research: Forty four Years of Computer Personnel Research: Achievements, Challenges \& the Future. ACM Press, New York, NY, 82. DOI : https://doi.org/10.1145/1125170.1125196

[20] Deborah R. Compeau and Christopher A. Higgins. 1995. Application of social cognitive theory to training for computer skills. Inf. Syst. Res. 6, 2 (1995), 118-143. DOI : https://doi.org/10.1287/isre.6.2.118

[21] Juliet M. Corbin and Anselm L. Strauss. 2014. Basics of Qualitative Research. Techniques and Procedures for Developing Grounded Theory (4th ed.). Sage, Los Angeles, London, New Delhi, Singpore, Washington DC, Boston.

[22] Malene F. Damholdt, Marco Nørskov, Ryuji Yamazaki, Raul Hakli, Catharina V. Hansen, Christina Vestergaard, and Johanna Seibt. 2015. Attitudinal change in elderly citizens toward social robots: The role of personality traits and beliefs about robot functionality. Front. Psychol. 6 (2015), 1701. DOI : https://doi.org/10.3389/fpsyg.2015.01701

[23] F. D. Davis. 1986. A Technology Acceptance Model for Empirically Testing New End-user Information Systems. Dissertation. Sloan School of Management. Massachusetts Institute of Technology, Cambridge, MA.

[24] Fred D. Davis. 1989. Perceived usefulness, perceived ease of use, and user acceptance of information technology. MIS Quart. 13, 3 (1989), 319-340. DOI : https://doi.org/10.2307/249008

[25] Fred D. Davis, Richard P. Bagozzi, and Paul R. Warshaw. 1989. User acceptance of computer technology. A comparison of two theoretical models. Manag. Sci. 35, 8 (1989), 982-1003. DOI : https://doi.org/10.1287/mnsc.35.8.982

[26] M. M. A. De Graaf and Somaya Ben Allouch. 2013. Exploring influencing variables for the acceptance of social robots. Robot. Auton. Syst. 61, 12 (2013), 1476-1486. DOI : https://doi.org/10.1016/j.robot.2013.07.007

[27] Fabian Dekker, Anna Salomons, and Jeroen van der Waal. 2017. Fear of robots at work: The role of economic selfinterest. Socioecon. Rev. 15, 3 (2017), 539-562. DOI : https://doi.org/10.1093/ser/mwx005

[28] Munjal Desai, Poornima Kaniarasu, Mikhail Medvedev, Aaron Steinfeld, and Holly Yanco. 2013. Impact of robot failures and feedback on real-time trust. In Proceedings of the 8th ACM/IEEE International Conference on HumanRobot Interaction (HRI'13). IEEE, 251-258. DOI : https://doi.org/10.1109/hri.2013.6483596

[29] Munjal Desai, Mikhail Medvedev, Marynel Vázquez, Sean McSheehy, Sofia Gadea-Omelchenko, Christian Bruggeman, Aaron Steinfeld, and Holly Yanco. 2012. Effects of changing reliability on trust of robot systems. In Proceedings of the 7th Annual ACM/IEEE International Conference on Human-Robot Interaction. ACM, New York, NY, 73-80.

[30] Munjal Desai, Kristen Stubbs, Aaron Steinfeld, and Holly Yanco. 2009. Creating trustworthy robots: Lessons and inspirations from automated systems. In Proceedings of the AISB Convention: New Frontiers in Human-Robot Interaction.

[31] Sarv Devaraj, Robert F. Easley, and J. M. Crant. 2008. Research note-How does personality matter? Relating the five-factor model to technology acceptance and use. Inf. Syst. Res. 19, 1 (2008), 93-105. DOI : https://doi.org/10.1287/ isre. 1070.0153

[32] Robert D. Dewar and Jane E. Dutton. 1986. The adoption of radical and incremental innovations. An empirical analysis. Manag. Sci. 32, 11 (1986), 1422-1433. DOI : https://doi.org/10.1287/mnsc.32.11.1422

[33] Mark T. Dishaw and Diane M. Strong. 1999. Extending the technology acceptance model with task-technology fit constructs. Inf. Manag. 36, 1 (1999), 9-21. DOI : https://doi.org/10.1016/S0378-7206(98)00101-3

[34] Martin Fishbein and Icek Ajzen. 1975. Belief, Attitude, Intention, and Behaviour: An Introduction to Theory and Research. Addison-Wesley, Reading, MA.

[35] S. R. Fletcher and P. Webb. 2017. Industrial robot ethics: The challenges of closer human collaboration in future manufacturing systems. In A World with Robots, Maria I. Aldinhas Ferreira, Joao Silva Sequeira, Mohammad O. Tokhi, Endre E. Kadar, and Gurvinder S. Virk, (Eds.). Intelligent Systems, Control and Automation: Science and Engineering. Springer, Cham, 159-169. DOI : https://doi.org/10.1007/978-3-319-46667-5_12

[36] Uwe Flick. 2011. An Introduction to Qualitative Research (4th ed.). Sage, Los Angeles, CA.

[37] Dieter Frey and Eva Jonas. 2002. Die theorie der kognizierten kontrolle. In Theorien der Sozialpsychologie. Band III. Motivations-, Selbst- und Informationsverarbeitungstheorien, Dieter Frey and Martin Irle, (Eds.). PsychologieLehrtexte/hrsg. von Dieter Frey und Martin Irle; 3. Huber, Bern, 13-50. 
[38] Marylene Gagne, Richard Koestner, and Miron Zuckerman. 2000. Facilitating acceptance of organizational change. The importance of self-determination. F. Appl. Soc. Psychol. 30, 9 (2000), 1843-1852. DOI : https://doi.org/10.1111/j. 1559-1816.2000.tb02471.x

[39] Ilaria Gaudiello, Elisabetta Zibetti, Sébastien Lefort, Mohamed Chetouani, and Serena Ivaldi. 2016. Trust as indicator of robot functional and social acceptance. An experimental study on user conformation to iCub answers. Comput. Hum. Behav. 61 (2016), 633-655. DOI : https://doi.org/10.1016/j.chb.2016.03.057

[40] Mahtab Ghazizadeh, John D. Lee, and Linda N. Boyle. 2012. Extending the technology acceptance model to assess automation. Cogn. Tech. Work 14, 1 (2012), 39-49. DOI : https://doi.org/10.1007/s10111-011-0194-3

[41] Sebastian Glende, Susann Klemcke, and Christoph Nedopil. 2013. Risiken der robotikakzeptanz-Identifikation und entwicklung von lösungsansätzen. In Lebensqualität im Wandel von Demografie und Technik. 6. Deutscher AALKongress mit Ausstellung, 22-23. VDE, Berlin.

[42] Anthony G. Greenwald and Mahzarin R. Banaji. 1995. Implicit social cognition. Attitudes, self-esteem, and stereotypes. Psychol. Rev. 102, 1 (1995), 4-27. DOI : https://doi.org/10.1037/0033-295x.102.1.4

[43] Peter A. Hancock, Deborah R. Billings, Kristin E. Schaefer, Jessie Y. C. Chen, Ewart J. de Visser, and Raja Parasuraman. 2011. A meta-analysis of factors affecting trust in human-robot interaction. Human Fact. 53, 5 (2011), 517-527. DOI : https://doi.org/10.1177/0018720811417254

[44] Marcel Heerink, Ben Krose, Vanessa Evers, and Bob Wielinga. 2010. Assessing acceptance of assistive social agent technology by older adults: The Almere model. Int. f. Soc. Robot. 2, 4 (2010), 361-375. DOI : https://doi.org/10.1007/ s12369-010-0068-5

[45] Melissa M. Henderson. 2015. Industrial Robot Acceptance: Effects of Workforce Demographics and Establishing a Culture of Acceptance Within Manufacturing Industry. Master's thesis. University of South Carolina, Columbia, SC.

[46] Pamela J. Hinds, Teresa L. Roberts, and H. Jones. 2004. Whose job is it anyway? A study of human-robot interaction in a collaborative task. Hum.-Comput. Interact. 19, 1 (2004), 151-181.

[47] Nerina L. Jimmieson, Deborah J. Terry, and Victor J. Callan. 2004. A longitudinal study of employee adaptation to organizational change: The role of change-related information and change-related self-efficacy. 7 . Occup. Health Psychol. 9, 1 (2004), 11-27. DOI : https://doi.org/10.1037/1076-8998.9.1.11

[48] Udo Kelle and Susann Kluge. 2010. Vom Einzelfall Zum Typus. Fallvergleich und Fallkontrastierung in Der Qualitativen Sozialforschung (2nd ed.). VS Verlag, Wiesbaden.

[49] J. Krüger, T. K. Lien, and A. Verl. 2009. Cooperation of human and machines in assembly lines. CIRP Ann.-Manuf. Technol. 58, 2 (2009), 628-646. DOI : https://doi.org/10.1016/j.cirp.2009.09.009

[50] Udo Kuckartz, Thorsten Dresing, Stefan Rädiker, and Claus Stefer. 2008. Qualitative Evaluation. Der Einstieg in die Praxis (2nd ed.). VS Verlag, Wiesbaden.

[51] Przemyslaw A. Lasota and Julie A. Shah. 2015. Analyzing the effects of human-aware motion planning on closeproximity human-robot collaboration. Hum. Fact. 57, 1 (2015), 21-33. DOI : https://doi.org/10.1177/0018720814565188

[52] Richard S. Lazarus. 1991. Progress on a cognitive-motivational-relational theory of emotion. Amer. Psychol. 46, 8 (1991), 819-834. DOI : https://doi.org/10.1037/0003-066X.46.8.819

[53] Paul Legris, John Ingham, and Pierre Collerette. 2003. Why do people use information technology? A critical review of the technology acceptance model. Inf. Manag. 40, 3 (2003), 191-204. DOI : https://doi.org/10.1016/S0378-7206(01) 00143-4

[54] Chien-Hsin Lin, Hsin-Yu Shih, and Peter J. Sher. 2007. Integrating technology readiness into technology acceptance. The TRAM model. Psychol. Mark. 24, 7 (2007), 641-657. DOI : https://doi.org/10.1002/mar.20177

[55] N. M. Lorenzi and R. T. Riley. 2000. Managing change. An overview. f. Amer. Med. Inf. Assoc. 7, 2 (2000), 116-124. DOI : https://doi.org/10.1136/jamia.2000.0070116

[56] Bruno Lotter and Hans-Peter Wiendahl. 2012. Montage in Der Industriellen Produktion. Ein Handbuch Für Die Praxis (2nd ed.). Springer, Berlin.

[57] Fred C. Lunenburg. 2011. Self-efficacy in the workplace: Implications for motivation and performance. Int. f. Manag. Bus. Admin. 14, 1 (2011).

[58] Nicolas Martin, Éric Jamet, and Séverine Erhel. 2016. From acceptibility to acceptance: Does experience with the product influence user initial representations? In Proceedings of the 18th International Human-Computer Interaction Conference, Proceedings, Part I, Constantine Stephanidis, (Ed.). Communications in Computer and Information Science. Springer, Cham, 128-133.

[59] Iñaki Maurtua, Aitor Ibarguren, Johan Kildal, Loreto Susperregi, and Basilio Sierra. 2017. Human-robot collaboration in industrial applications: Safety, interaction and trust. Int. F. Adv. Robot. Syst. 14, 4 (2017), 172988141771601. DOI : https://doi.org/10.1177/1729881417716010

[60] Paul K. McClure. 2018. "You're fired," says the robot: The rise of automation in the workplace, technophobes, and fears of unemployment. Soc. Sci. Comput. Rev. 36, 2 (2018), 139-156. DOI : https://doi.org/10.1177/0894439317698637

[61] D. H. Mcknight, Michelle Carter, Jason B. Thatcher, and Paul F. Clay. 2011. Trust in a specific technology. ACM Trans. Manag. Inf. Syst. 2, 2 (2011), 1-25. DOI : https://doi.org/10.1145/1985347.1985353 
[62] Nicole Mirnig, Gerald Stollnberger, Markus Miksch, Susanne Stadler, Manuel Giuliani, and Manfred Tscheligi. 2017. To err is robot. How humans assess and act toward an erroneous social robot. Front. Robot. AI 4, 227. DOI: https://doi.org/10.3389/frobt.2017.00021

[63] Gary C. Moore and Izak Benbasat. 1991. Development of an instrument to measure the perceptions of adopting an information technology innovation. Inf. Syst. Res. 2, 3 (1991), 192-222. DOI : https://doi.org/10.1287/isre.2.3.192

[64] Umit Morsunbul. 2019. Human-robot interaction: How do personality traits affect attitudes towards robot? 116,2 (2019), 499-504. Retrieved from https://www.j-humansciences.com/ojs/index.php/IJHS/article/view/5636.

[65] Rainer Müller, Matthias Vette, and Ortwin Mailahn. 2016. Process-oriented task assignment for assembly processes with human-robot interaction. Procedia CIRP 44 (2016), 210-215. DOI : https://doi.org/10.1016/j.procir.2016.02.080

[66] Sarah L. Müller and Anja Richert. 2018. The big-five personality dimensions and attitudes to-wards robots: A crosssectional study. In Proceedings of the 11th PErvasive Technologies Related to Assistive Environments Conference- (PETRA'18). ACM Press, New York, NY, 405-408. DOI : https://doi.org/10.1145/3197768.3203178

[67] Dmitriy A. Nesterkin. 2013. Organizational change and psychological reactance. f. Org. Change Manag. 26, 3 (2013), 573-594. DOI : https://doi.org/10.1108/09534811311328588

[68] Tatsuya Nomura. 2014. Influences of experiences of robots into negative attitudes toward robots. In Proceedings of the 23rd IEEE International Symposium on Robot and Human Interactive Communication (RO-MAN'14). IEEE, Piscataway, NJ, 460-464. DOI : https://doi.org/10.1109/ROMAN.2014.6926295

[69] Benjamin C. Oistad, Catherine E. Sembroski, Kathryn A. Gate, Margaret M. Krupp, Marlena R. Fraune, and Selma Šabanović. 2016. Colleague or tool? Interactivity increases positive perceptions of and willingness to interact with a robotic co-worker. In Proceedings of the 8th International Conference on Social Robotics (ICSR'16), Arvin Agah, John-John Cabibihan, Miguel A. Salichs and Hongsheng He, (Eds.). Springer, Cham, 774-785.

[70] Kristin E. Oleson, D. R. Billings, Vivien Kocsis, Jessie Y. C. Chen, and P. A. Hancock. 2011. Antecedents of trust in human-robot collaborations. In Proceedings of the IEEE International Multi-Disciplinary Conference on Cognitive Methods in Situation Awareness and Decision Support (CogSIMA'11). IEEE, 175-178. DOI : https://doi.org/10.1109/ COGSIMA.2011.5753439

[71] Richard L. Oliver. 1980. A cognitive model of the antecedents and consequences of satisfaction decisions. F. Market. Res. 17, 4 (1980), 460-469. DOI : https://doi.org/10.2307/3150499

[72] Shaul Oreg, Maria Vakola, and Achilles Armenakis. 2011. Change recipients' reactions to organizational change. f. Appl. Behav. Sci. 47, 4 (2011), 461-524. DOI : https://doi.org/10.1177/0021886310396550

[73] Natalia Reich and Friederike Eyssel. 2013. Attitudes towards service robots in domestic environments: The role of personality characteristics, individual interests, and demographic variables. Paladyn, f. Behav. Robot. 4, 2 (2013). DOI : https://doi.org/10.2478/pjbr-2013-0014

[74] Jakob Reinhardt, Jonas Schmidtler, Moritz Körber, and Klaus Bengler. 2016. Follow Me! Wie Roboter Menschen führen sollen. Z. Arb. Wiss. 70, 4 (2016), 203-210. DOI : https://doi.org/10.1007/s41449-016-0039-2

[75] Maha Salem, Friederike Eyssel, Katharina Rohlfing, Stefan Kopp, and Frank Joublin. 2013. To err is human(-like): Effects of robot gesture on perceived anthropomorphism and likability. Int. F. Soc. Robot. 5, 3 (2013), 313-323. DOI : https://doi.org/10.1007/s12369-013-0196-9

[76] Maha Salem, Gabriella Lakatos, Farshid Amirabdollahian, and Kerstin Dautenhahn. 2015. Would you trust a (faulty) robot? In Proceedings of the 10th Annual ACM/IEEE International Conference on Human-Robot Interaction (HRI'15). ACM Press, New York, NY, 141-148. DOI : https://doi.org/10.1145/2696454.2696497

[77] William Samuelson and Richard Zeckhauser. 1988. Status quo bias in decision making. f. Risk Uncert. 1, 1 (1988), 7-59. DOI : https://doi.org/10.1007/BF00055564

[78] Nina Savela, Tuuli Turja, and Atte Oksanen. 2018. Social acceptance of robots in different occupational fields: A systematic literature review. Int. F. Soc. Robot. 10, 4 (2018), 493-502. DOI : https://doi.org/10.1007/s12369-017-0452-5

[79] Martina Schäfer and Dorothee Keppler. 2013. Modelle Der Technikorientierten Akzeptanzforschung. Überblick und Reflexion am Beispiel eines Forschungsprojekts zur Implementierung Innovativer Technischer EnergieeffizienzMaßnahmen. Discussion paper 34. Zentrum Technik und Gesellschaft, Berlin.

[80] Jonas Schmidtler, Verena Knott, Christin Hölzel, Klaus Bengler, Christopher M. Schlick, and Jennifer Bützler. 2015. Human centered assistance applications for the working environment of the future. Occup. Ergon. 12, 3 (2015), 83-95. DOI : https://doi.org/10.3233/OER-150226

[81] Petra Schweizer-Ries, Irina Rau, Jan Zoellner, Katrin Nolting, Johannes Rupp, and Dorothee Keppler. 2010. Aktivität und Teilhabe-Akzeptanz Erneuerbarer Energien durch Beteiligung steigern. Projektabschlussbericht, Magdeburg $\&$ Berlin.

[82] Yuhyung Shin, Won-Moo Hur, Tae W. Moon, and Soomi Lee. 2019. A motivational perspective on job insecurity: Relationships between job insecurity, intrinsic motivation, and performance and behavioral outcomes. Int. f. Environ. Res. Pub. Health 16, 10 (2019). DOI : https://doi.org/10.3390/ijerph16101812 
[83] Cory-Ann Smarr. 2013. Towards a Qualitative Framework of Acceptance of Personal Robots. Dissertation. Georgia Institute of Technology, Atlanta, GA.

[84] Cory-Ann Smarr, Akanksha Prakash, Jenay M. Beer, Tracy L. Mitzner, Charles C. Kemp, and Wendy A. Rogers. 2012. Older adults' preferences for and acceptance of robot assistance for everyday licing tasks. Proc. Hum. Fact. Ergon. Soc. 56, 1 (2012), 153-157. DOI : https://doi.org/10.1177/1071181312561009

[85] SocioCultural Research Consultants. 2017. Dedoose. Retrieved from https://www.dedoose.com/.

[86] Alex W. Stedmon, Hannah Howells, John R. Wilson, and Iman Dianat. 2012. Ergonomics/Human factors needs of an aging workforce in the manufacturing sector. Health Prom. Persp. 2, 2 (2012), 112-125. DOI : https://doi.org/10.5681/ hpp.2012.014

[87] Jan-Philipp Stein, Benny Liebold, and Peter Ohler. 2019. Stay back, clever thing! Linking situational control and human uniqueness concerns to the aversion against autonomous technology. Comput. Hum. Behav. 95 (2019), 7382. DOI : https://doi.org/10.1016/j.chb.2019.01.021

[88] Jörg Strübing. 2014. Grounded Theory. Zur Sozialtheoretischen und Epistemologischen Fundierung Eines Pragmatistischen Forschungsstils (3rd ed.). Qualitative Sozialforschung. Springer, Wiesbaden.

[89] Gunnvald B. Svendsen, Jan-Are K. Johnsen, Live Almås-Sørensen, and Joar Vittersø. 2013. Personality and technology acceptance: The influence of personality factors on the core constructs of the Technology Acceptance Model. Behav. Inf. Technol. 32, 4 (2013), 323-334. DOI : https://doi.org/10.1080/0144929X.2011.553740

[90] Tracy A. Sykes, Viswanath Venkatesh, and Sanjay Gosain. 2009. Model of acceptance with peer support: A social network perspective to understand employees' system use. MIS Quart. 33, 2 (2009), 371-394.

[91] Mahin Tavakoli. 2010. A positive approach to stress, resistance, and organizational change. Procedia-Soc. Behav. Sci. 5 (2010), 1794-1798. DOI : https://doi.org/10.1016/j.sbspro.2010.07.366

[92] Shirley Taylor and Peter Todd. 1995. Assessing IT usage. The role of prior experience. MIS Quart. 19, 4 (1995), 561570. DOI : https://doi.org/10.2307/249633

[93] Ronald L. Thompson, Christopher A. Higgins, and Jane M. Howell. 1991. Personal computing. Toward a conceptual model of utilization. MIS Quart. 15, 1 (1991), 125-143. DOI : https://doi.org/10.2307/249443

[94] Viswanath Venkatesh. 2000. Determinants of perceived ease of use. Integrating control, intrinsic motivation, and emotion into the technology acceptance model. Inf. Syst. Res. 11, 4 (2000), 342-365. DOI : https://doi.org/10.1287/isre. 11.4.342.11872

[95] Viswanath Venkatesh and Hillol Bala. 2008. Technology acceptance model 3 and a research agenda on interventions. Decis. Sci. 39, 2 (2008), 273-315. DOI : https://doi.org/10.1111/j.1540-5915.2008.00192.x

[96] Viswanath Venkatesh and Fred D. Davis. 2000. A theoretical extension of the technology acceptance model. Four longitudinal field studies. Manag. Sci. 46, 2 (2000), 186-204. DOI : https://doi.org/10.1287/mnsc.46.2.186.11926

[97] Viswanath Venkatesh, Michael G. Morris, Gordon B. Davis, and Fred D. Davis. 2003. User acceptance of information technology: Toward a unified view. MIS Quart. 27, 3 (2003), 425-478.

[98] Kristin Vogelsang, Melanie Steinhüser, and Uwe Hoppe. 2013. A qualitative approach to examine technology acceptance. In Proceedings of the 34th International Conference on Information Systems. Association for Information Systems. AIS Electronic Library (AISeL), Atlanta, GA, 1-16.

[99] Mary-Anne Williams. 2016. Decision-theoretic human-robot interaction: Designing reasonable and rational robot behavior. In Proceedings of the 8th International Conference on Social Robotics (ICSR'16). Lecture Notes in Computer Science-Lecture Notes in Artificial Intelligence, 9979. Springer International Publishing, Cham, 72-82. DOI : https://doi.org/10.1007/978-3-319-47437-3_8

[100] Philip F. Wu. 2012. A mixed methods approach to technology acceptance research. f. Assoc. Inf. Syst. 13, 3 (2012), 172-187.

[101] Ya-Huei Wu, Jérémy Wrobel, Mélanie Cornuet, Hélène Kerhervé, Souad Damnée, and Anne-Sophie Rigaud. 2014. Acceptance of an assistive robot in older adults: A mixed-method study of human-robot interaction over a onemonth period in the living lab setting. Clin. Interven. Aging 9 (2014), 801-811. DOI: https://doi.org/10.2147/CIA. S56435

[102] Rosemarie E. Yagoda and Douglas J. Gillan. 2012. You want me to trust a robot? The development of a human-robot interaction trust scale. Int. F. Soc. Robot. 4, 3 (2012), 235-248. DOI : https://doi.org/10.1007/s12369-012-0144-0

[103] Sangseok You, Jeong-Hwan Kim, SangHyun Lee, Vineet Kamat, and Lionel P. Robert. 2018. Enhancing perceived safety in human-robot collaborative construction using immersive virtual environments. Autom. Constr. 96 (2018), 161-170. DOI: https://doi.org/10.1016/j.autcon.2018.09.008

[104] James E. Young, JaYoung Sung, Amy Voida, Ehud Sharlin, Takeo Igarashi, Henrik I. Christensen, and Rebecca E. Grinter. 2011. Evaluating human-robot interaction. Int. Soc. Robot. 3, 1 (2011), 53-67. DOI : https://doi.org/10.1007/ s12369-010-0081-8 
[105] Andrea M. Zanchettin, Luca Bascetta, and Paolo Rocco. 2013. Acceptability of robotic manipulators in shared working environments through human-like redundancy resolution. Appl. Ergon. 44, 6 (2013), 982-989. DOI: https://doi.org/10.1016/j.apergo.2013.03.028

[106] Jakub Złotowski, Kumar Yogeeswaran, and Christoph Bartneck. 2017. Can we control it? Autonomous robots threaten human identity, uniqueness, safety, and resources. Int. F. Hum.-Comput. Stud. 100, 48-54. DOI: https://doi.org/10.1016/j.ijhcs.2016.12.008

Received January 2019; revised February 2020; accepted May 2020 